\title{
DEFICIÊNCIA HÍDRICA SIMULADA NOS DIFERENTES ESTÁDIOS DE DESENVOLVIMENTO DE UM CULTIVAR PRECOCE DE SOJA (')
}

\author{
SANDRA DOS SANTOS SEVÁ NOGUEIRA $(2,4)$ \\ e VIOLETA NAGAI ${ }^{3}$ )
}

\begin{abstract}
RESUMO
Estudou-se o efeito da deficiência hídrica em diferentes estádios do cultivar precoce de soja Paraná. As plantas foram cultivadas em casa de vegetação, em solução nutritiva de Hoagland. A deficiência hídrica foi simulada pela adição de polietilenoglicol (PEG) $6 \%$ na solução nutritiva, nos seguintes estádios: vegetativo, florescimento e enchimento do grão. Os resultados mostraram que: (1) a deficiência hídrica nos três estádios diminuiu a produção e o número de vagens e de grãos em relação à testemunha; (2) no período do enchimento do grão diminuiu o peso do grão e a produção, com relação ao estádio vegetativo. Concluiu-se que a deficiência foi mais prejudicial nos estádios reprodutivos, devido à diminuição da produção de grăos.
\end{abstract}

Termos de indexaçāo: soja, Glycine max (L.) Merrill, deficiência hídrica, produçăo.

(1) Trabalho apresentado no IV Seminário Nacional de Pesquisa de Soja, 1986, Porto Alegre. Recebido para publicação em 27 de janeiro e aceito em 20 de outubro de 1987.

(2) Seção de Fisiologia, Instituto Agronômico (IAC), Caixa Postal 28, 13001 Campinas (SP).

(3) Seção de Técnica Experimental e Cálculo (IAC).

$\left({ }^{4}\right)$ Com bolsa de pesquisa do CNPq. 


\section{INTRODUÇÃO}

A expansão da cultura da soja no Brasil introduziu-a aos mais diversos ambientes climáticos e edáficos, exigindo o melhoramento de cultivares adaptados às condições brasileiras e regionais.

O melhoramento dos cultivares, realizado principalmente com base na resposta fotoperiódica e na disponibilidade de nutrientes (fertilidade do solo), tem concorrida para um aùmento real na produtividade. Aumentos adicionais poderāo ocorrer através do conhecimento do efeito dos fatores climáticos na fisiologia da planta.

A água disponivel no solo é um dos fatores mais importantes na produtividade vegetal. A deficiência hídrica pode levar a planta a uma diminuição considerável na produção, mesmo em cultivares de excelente potencial genético. Condições hídricas perfeitas são raras e a deficiência hídrica é, em geral, mais uma regra do que uma exceção.

A água é um fator importante em qualquer fase do desenvolvimento da cultura da soja porque está envolvida diretamente nos processos metabólicos vitais, ou seja, na fotossíntese e na respiração.

Entretanto, segundo alguns autores (RUNGE \& ODELL, 1960; SHAW \& LAING, 1966, e SIONIT \& KRAMER, 1977), o efeito da deficiência hídrica em soja é variável com o estádio de desenvolvimento da planta no qual ocorre. Observações do primeiro autor constatam que a duraçāo do ciclo do cultivar, função da duraçāo de cada estádio, é fator de variação no efeito da deficiência hídrica em determinado estádio.

O uso do polietilenoglicol (PEG) é uma técnica utilizada em experimentos em casa de vegetação, onde é possivel um controle mais efetivo do ambiente.

O polietilenoglicol, comercialmente conhecido como Carbowax, é um polímero químico de cadeia longa, de alto peso molecular, inerte, não iônico, altamente solúvel em água (LAGERWERFF et al., 1961). É um agente com capacidade de aumentar a concentração osmótica das soluções nutritivas utilizadas em experimentos com plantas. Segundo LAWLOR (1970), o PEG simula uma seca, causando dissecação na planta, porque bloqueia o movimento da água pela diminuição do potencial da água do meio onde crescem as raizes. A planta, absorvendo menos água, vai diminuir o potencial da água nas folhas $e$, conseqüentemente, todo o metabolismo é alterado.

O presente estudo é parte de um projeto mais amplo, no qual os autores têm utilizado várias alternativas para o estudo dos efeitos da deficiência hídrica em soja: cultivares, dosagens de PEG e épocas de ocorrência da deficiência hídrica. Pesquisas anteriores mostraram que, em cultivares de ciclo longo, nos quais os estádios de desenvolvimento são intrinsecamente maiores, a deficiência hídrica em determinado periodo é menos prejudicial do que em cultivares de ciclo curto porque, nos primeiros, a planta dispōe de um tempo mais longo em cada 
periodo para recuperar-se dos efeitos de uma seca, desde que ela não ocorra durante todo o ciclo.

Esta pesquisa teve como objetivo verificar o efeito da deficiência hidrica simulada nos diferentes estádios de desenvolvimento do cultivar de soja precoce Paraná.

\section{MATERIAL E MÉTODOS}

O projeto foi executado em casa de vegetação da Seção de Fisiologia, do Instituto Agronômico de Campinas, durante o ano agrícola de 1984/85. Utilizou-se o cultivar de soja Paraná, de ciclo curto e porte baixo.

Colocaram-se as sementes para germinar em areia, transferindo-se as plântulas para solução nutritiva de Hoagland quando aparecia o primeiro par de folhas trifoliadas. Os vasos, construídos com tubos de $\mathrm{PVC}$ rígidos, com $50 \mathrm{~cm}$ de altura e $10 \mathrm{~cm}$ de diâmetro, foram pintados externamente com tinta alumínio para refletir o calor. Em cada vaso contendo solução nutritiva, colocava-se uma planta que permanecia até a produção. A deficiência hídrica foi simulada pela adiçāo de polietilenoglicol (Carbowax 600) à solução de Hoagland, nos diferentes estádios de desenvolvimento, segundo o tratamento.

Escolheu-se a concentração de $6 \%$ de PEG na solução, a qual induziu um potencial osmótico de $-0,335 \mathrm{MPa}$, capaz, segundo observaçōes preliminares do primeiro autor, de simular uma seca e alterar o comportamento da planta, em condiçōes experimentais.

O delineamento adotado foi o inteiramente casualizado, com quatro tratamentos e sete repetições por tratamento, sendo cada planta uma repetição.

Os tratamentos utilizados foram os seguintes: $T$ (testemunha), A (solução nutritiva $+6 \%$ PEG no periodo vegetativo), $B$ (solução nutritiva $+6 \%$ PEG no florescimento) e $C$ (solução nutritiva $+6 \% \mathrm{PEG}$ no enchimento do grão).

Os parâmetros fisiológicos analisados foram: número de vagens por planta, número de grãos e produção (peso) de grãos por planta e peso médio do grão.

A comparação múltipla de médias foi feita com os testes de Dunnett e de Duncan. O teste de Dunnett foi empregado para as comparações dos estádios em relação à testemunha e o teste de Duncan para comparar os estádios.

\section{RESULTADOS E DISCUSSÃO}

Verificou-se que a produção de grãos por planta diferiu da testemunha com a deficiência hídrica simulada em qualquer um dos três estádios (Quadro 1). Esse comportamento foi também observado por SHAW \& LAING (1966) e SIONIT \& KRAMER (1977). 
QUADRO 1. Efeito da deficiência hídrica simulada no estádio vegetativo (A), florescimento (B) e enchimento do grão (C), na produção de grãos, número de vagens, número de grãos e peso do grão, no cultivar precoce de soja Paraná, quando comparado com a testemunha $(\mathrm{T})$

\begin{tabular}{lccc}
\hline Tratamento Produção de grãos & $\begin{array}{c}\text { Número de vagens } \\
\text { por planta }\end{array}$ & $\begin{array}{c}\text { Número de grãos } \\
\text { por planta }\end{array}$ & Peso do grão \\
\hline
\end{tabular}

\begin{tabular}{llrll}
\multicolumn{9}{c}{ g/planta } & & & 9 \\
T & $41,38 \mathrm{~A}$ & $105,71 \mathrm{~A}$ & $263,57 \mathrm{~A}$ & $0,157 \mathrm{~B}$ \\
$\mathrm{~A}$ & $34,82 \mathrm{Ba}$ & $81,86 \mathrm{Ba}$ & $190,14 \mathrm{Bb}$ & $0,182 \mathrm{Aa}$ \\
$\mathrm{B}$ & $31,38 \mathrm{Bab}$ & $74,42 \mathrm{Ba}$ & $183,42 \mathrm{Bb}$ & $0,170 \mathrm{Bab}$ \\
$\mathrm{C}$ & $27,81 \mathrm{Bb}$ & $79,00 \mathrm{Ba}$ & $205,71 \mathrm{Bab}$ & $0,135 \mathrm{Bc}$
\end{tabular}

Médias acompanhadas da mesma letra não diferem entre si ao nivel de $5 \%$. Letras maiúsculas indicam cornparaçôes com a testemunha, feitas pelo teste de Dunnett; letras minúsculas referem-se ao teste de Duncan para comparação entre estádios.

$O$ número de vagens por planta diminuiu significativamente $(P<0,05)$ em todos os tratamentos, com relação à testemunha, indicando que a deficiência hídrica afetou essa característica em qualquer um dos estádios onde ocorreu. Por outro lado, não houve diferença entre os estádios nesse aspecto fisiológico. Isso está em concordância com BLANCHET et al. (1977, 1980), que verificaram ser o número de vagens por planta a característica mais afetada pela seca. Segundo BOYER (1976), as estruturas florais e, conseqüentemente, a polinização, ficam severamente comprometidas sob deficiência hídrica.

O número de grãos por planta diminuiu significativamente com a deficiência hidrica em relação à testemunha, não havendo, no entanto, diferenças entre estádios.

O peso do grão diminuiu quando a deficiência hídrica ocorreu no estádio do enchimento do grão em relação aos demais estádios. Como o número de grãos deste tratamento não diferiu do dos períodos vegetativo e florescimento, 0 decréscimo da produção pode ser atribuído à diminuição no peso do grão.

SIONIT \& KRAMER (1977) observaram também uma diminuição no peso do grão de soja quando a deficiência hídrica ocorreu no estádio de enchimento do grāo.

Verificou-se que tanto a produção de grãos quanto o peso do grão diferiram entre os estádios vegetativo e enchimento do grão. É conhecida a diminuicão na produção de grãos sob deficiência hídrica, causada pela diminuição da fotossintese. No entanto, a relação exata dessa diminuição com a produção é desconhecida (BOYER, 1976). Segundo WARDLAW (1968), as reservas acumuladas durante o ciclo da planta são mais importantes para a produção de grãos do que a fotossíntese em determinado estádio, ou seja, a produção está correlacionada 
com a fotossíntese global ocorrida durante o ciclo. Daí, pode-se levantar a hipótese da existência de um processo compensatório para produção ao longo do ciclo da planta.

Como a produção de grãos é a meta principal do agricultor, ponderou-se que a deficiência hídrica foi mais danosa quando ocorreu durante o estádio de enchimento do grāo.

\title{
4. CONCLUSÕES
}

1. Entre as características avaliadas, a produção de grãos foi a única relevante no tipo de abordagem do trabalho.

2. A deficiência hídrica simulada no estádio de enchimento do grão foi mais danosa à produção do que no vegetativo.

\section{SUMMARY}

\section{EFFECT OF SIMULATED WATER STRESS DURING DIFFERENT STAGES OF THE EARLY SOYBEAN CULTIVAR PARANÁ}

\begin{abstract}
A greenhouse experiment was carried out to study the effect of simulated water stress during different growth stages on the yield of the early soybean cultivar Paraná, in Campinas, State of São Paulo, Brazil. The water stress was simulated by the addition of PEG (polyetilenoglycol) to the Hoagland nutrient solution where the plants were cultivated, up to three different stages: vegetative period, flowering period and pod filling period. It was observed that water stress during the three periods reduced the grain yield, the seed weight and the seed number. The water stress was more damaging during the reproductive stages for the cultivar studied since it reduced the grain yield.
\end{abstract}

Index terms: soybean, Glycine max (L.) Merrill, water deficiency, production.

\section{REFERÊNCIAS BIBLIOGRÁFICAS}

BLANCHET, R.; GELFI, N. \& BOSCO, M. Relations entre consommation d'eau et production chez divers types variétaux de soja. Annales Agronomiques, 28:261-275, 1977.

d'alimentation hydrique sur la biologie et la production du soja. Informations Techniques Cetion, 71:12-21, 1980.

BOYER, J.S. Water deficits and photosynthesis. In: KOZLOWSKI, T.T.,'ed. Water deficits and plant growth. New York, Academic Press, 1976. v.4, p.153-190. 
GHORASHY, S.R.; PENDLETON, J.W.; PETERS, J.B.; BOYER, J.S. \& BURLEIN, J.E. Internal water stress and apparent photosynthesis with soybeans differing in pubescence. Agronomy Journal, 63:674-675, 1971.

LAGERWERFF, J.W.; OGATA, G \& EAGLE, H.E. Control of osmotic pressure of culture solutions with polyethylenoglicol. Science, 133:1486-1487, 1961.

LAWLOR, D.W. Absorption of polyethylenoglicols by plants and their effects on plant growth. New Phytologist, 69:501-513, 1970.

RUNGE, E.C.A. \& ODELL, R.T. The relation between precipitation, temperature and yield of soybeans in the Agronomy South Farm, Urbana, Illinois. Agronomy Journal, 52:245-247, 1960.

SHAW, R.H. \& LAING, D.R. Moisture stress and plant response. In: PIERRE, W.H.; DIRKMAN, D.; PERK, J. \& SHAW, R.H., eds. Plant environment and efficient water use. Wisconsin, American Society of Agriculture and Soil Science Society America, 1966. p.73-94.

SIONIT, N. \& KRAMER, P.J. Effects of water stress during different stages of growth of soybean. Agronomy Journal, 69:274-278, 1977.

WARDLAW, I.F. The effect of water stress on translocation in relation to photosynthesis and growth. I. Effect during grain development in wheat. Australian Journal of Biological Science, 20:25-39, 1968. 